\title{
Artigos
}

Fabiana de Oliveira'

Anete Abramowicz ${ }^{2}$

\section{Políticas Públicas e Direitos das Crianças: uma reflexão a partir da perspectiva étnico-racial}

Resumo: Apesar de nos últimos anos termos vivido uma abertura para o debate das questões relacionadas à raça no Brasil ocasionando mudanças consideráveis no debate contemporâneo a discriminação relacionada à questão racial ainda é uma variável estrutural na nossa realidade, sendo que a educação visibiliza esta desigualdade racial em seus indicadores educacionais e na micropolítica de cada instituição de educação infantil. Assim as crianças pequenas e negras sofrem uma dupla desigualdade social: são pequenas e negras. Por meio desse ensaio de natureza reflexiva buscamos discutir às questões relacionadas às políticas públicas e aos direitos das crianças negras à educação. A relevância para o desenvolvimento do trabalho se pauta na exiguidade de estudos envolvendo políticas públicas, educação e infância a partir dos recortes de idade e raça no Brasil.

Palavras-chave: Políticas públicas. Direitos. Crianças. Idade. Étnico-racial.

\section{Public Policies and Children's Rights: a reflection from the ethnic-racial perspective}

Abstract: Despite the fact that in recent years we have been open to discussing racerelated issues in Brazil, bringing about considerable changes in the contemporary debate, discrimination related to race is still a structural variable in our reality, and education shows this racial inequality in its educational indicators and in the micropolitics of each kindergarten. The black and small children suffer a double social inequality: they are small and black. Through this reflexive essay we seek to discuss issues related to public policies and the rights of black children to education. The relevance for the development of the work is based on the smallness of studies involving public policies, education and childhood from the age and race in Brazil.

Keywords: Public policies. Rights. Children. Age. Ethnic-racial.

\footnotetext{
' Doutora em Educação pela Universidade Federal de São Carlos (UFSCar). Docente do Programa de PósGraduação em Educação da universidade Federal de Alfenas (UNIFAL-MG). E-mail: fabiana.oliveiraunifal@gmail.com

2 Doutora em Educação pela Universidade Estadual de Campinas. Professora Titular do Centro de Educação e Ciências Humanas da UFSCar. Bolsista Produtividade CNPQ. E-mail: aneteabramo@gmail.com
} 


\section{Introdução}

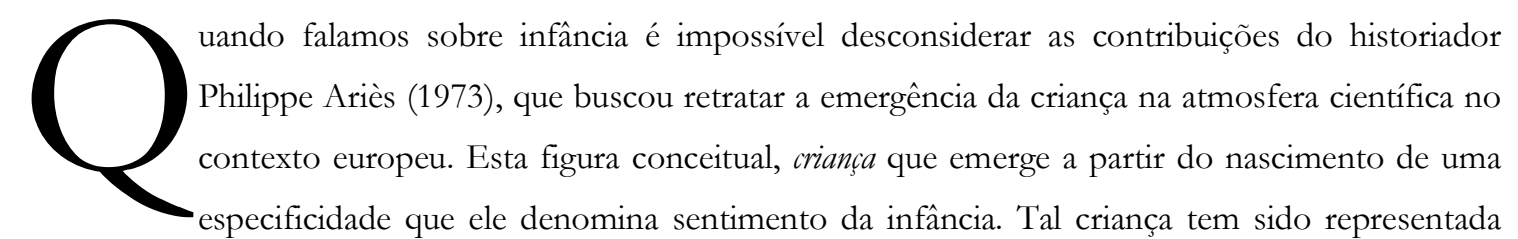
como branca, cuja essência vem sendo disputada entre os pedagogos, filósofos, religiosos etc.: ora como má, ora como boa, ora em perigo, ou perigosa. No entanto, neste trabalho emerge uma infância branca que acabou se generalizando. E a criança negra, e sua infância?

Apesar das crianças estarem sendo alvo de inúmeras pesquisas e o interesse sobre elas aumentado, também tem crescido as desigualdades vividas por inúmeras crianças no nosso país. As desigualdades de gênero e de raça possuem suas especificidades, mas conjuntamente se soma e são acrescidas a um terceiro aspecto: a pobreza, gerando maior vulnerabilidade. As crianças acabam sendo as maiores vítimas das condições de exclusão.

As crianças compõem um grupo, uma população, ou povo ( segundo Alain, 1932) que é tratada de forma subalternizada, ocupando um status social marginal pois pertence a geração que se define por sua idade, quanto menor a idade, menor seu status social, menor sua hierarquia nas ordens sociais, discursivas etc. Justamente é esse fator que define a separação entre adultos e crianças na sociedade e que também caracteriza esse período da vida denominado infância e que constitui relações de dominação dos adultos em relação às crianças.

Neste sentido, apesar de nos últimos anos termos vivido uma abertura para o debate das questões relacionadas à raça no Brasil ocasionando mudanças consideráveis no debate contemporâneo a discriminação relacionada à questão racial ainda é uma variável estrutural na nossa realidade, o que dificulta a concretização de uma sociedade mais igualitária, justa e não discriminatória, sendo que a educação visibiliza, e também a acentua, esta desigualdade racial em seus indicadores educacionais e na micropolítica de cada escola, de cada creche. Ou seja, as crianças pequenas e negras sofrem uma dupla desigualdade social: são pequenas, crianças e negras, muitas pobres e meninas, várias hierarquias sociais se sobrepondo.

Assim, por meio desse ensaio, buscamos discutir as questões relacionadas às políticas públicas e aos direitos das crianças negras à educação que vivem em sua maioria uma infância fortemente marcada pelas questões de desigualdades ocasionadas pela cor da sua pele e por sua condição social, muitas vezes marcada pela vulnerabilidade e pobreza. A relevância para o desenvolvimento do trabalho se pauta na exiguidade de estudos envolvendo políticas públicas, educação e infância a partir dos recortes de gênero e raça no Brasil, além de constituir mais um subsídio para o questionamento de práticas de homogeneidade e racismo ainda presentes na nossa educação e que também atinge as crianças pequenas desde a educação 
infantil. Para isso nos apoiaremos em alguns campos teóricos, entre eles: Sociologia da Infância e também das pesquisas envolvendo as discussões sobre relações étnico-raciais.

A Sociologia da Infância nos ajudará a refletir sobre as condições de vida das crianças compreendendo estas como atores sociais, pois participam da sociedade e a infância como categoria geracional construída socialmente e que dependendo do contexto em que estão inseridas vivem uma situação de exclusão social. Neste sentido, a Sociologia da Infância poderá contribuir para o questionamento dessas condições de subalternidade e exclusão em que vivem as crianças, bem como, refletir sobre as possibilidades de emancipação social da infância (Sarmento, 2009) a partir da discussão das políticas públicas para a educação da criança pequena e dos seus direitos. Segundo Qvortrup (2009) infância e política estão totalmente relacionadas, pois mesmo quando as políticas elaboradas pelos adultos não têm as crianças como foco, ainda sim, podem ter grandes consequências na vida delas, sendo irreal mantê-las fora da economia e da política.

Nesse artigo estamos compreendendo raça e infância como duas categorias totalmente autônomas, pois como bem coloca Apple (2001), classe, gênero, realidades coloniais e pós-coloniais, cada uma tem sua própria história e são relativamente autônomas, mas podem estar implicadas e relacionadas com a construção social da raça.

De acordo com Omi e Winant (1994 apud Apple, 2001, p.61) "a raça é parte constitutiva de muitas de nossas experiências cotidianas", no entanto, tal relação também pode ser pensada a partir da questão de gênero, pois desde que nascem a identidade das crianças vai sendo constituída a partir desse parâmetro também, sendo ambos uma construção social, cultural e histórica.

Para fazer essa discussão sobre políticas educacionais e as questões de gênero e de raça não podemos deixar de discutir também o conceito de diversidade e de diferença, pois temos visto a existência pacífica dos dois conceitos, sendo utilizados em alguns casos até mesmo como sinônimos e a nossa perspectiva teórica adotada não permite tal condescendência.

Segundo Silvério (2006) há três perspectivas que podemos considerar mais presentes no discurso sobre a diversidade brasileira referente à educação, vejamos: primeira, o conceito de diversidade está associado à noção de exclusão social e que está atrelada à questão da pobreza, racial, de gênero, etc. tendo o fator econômico como explicação das desigualdades; segunda, faz parte dos debates ambientalistas no qual a questão principal é a sustentabilidade na biodiversidade; e, por última, segundo o autor podemos denominála como aquela que "afirma o direito à diferença" e está ligada principalmente às lutas antirracistas a partir da década de 70 com o Movimento Negro Unificado (SILVÉRIO, 2006, p.10-11).

Associado às lutas do Movimento Negro podemos também mencionar a participação das mulheres, nos Movimentos Feministas que também buscaram a superação das desigualdades e lutaram pelos direitos das mulheres. São dois Movimentos Sociais com vertentes diferentes, que levantam bandeiras que não são similares, mas ao mesmo tempo, são bandeiras que defendem um ideal de igualdade, de justiça e de direitos para os grupos ditos minoritários como os negros e as mulheres. 
A partir disso iremos discutir as possibilidades de políticas públicas pós-colonialistas para a infância que não se pautam em uma concepção universal de infância.

\section{Raça e Políticas Públicas}

De acordo com Rossetti-Ferreira et al (2002) apesar de ter ocorrido alguns avanços em relação à taxa de mortalidade infantil no Brasil e Peru e a de fertilidade na América Latina e no Caribe terem diminuído, isso ainda é insatisfatório quando comparado aos países desenvolvidos, havendo a necessidade de melhoria no nível educacional, distribuição mais igualitária de renda e melhoria das condições de vida e, somando-se a isso, as autoras concluem que "há uma desigualdade interna nos países que é atravessada pela questão de gênero, condições econômicas e zona de moradia e também pela questão étnica" (Rossetti-Ferreira, Ramon e Silva, 2002, p.83).

Rosemberg (2002) afirma que as políticas de educação infantil nos países subdesenvolvidos têm sido fortemente influenciadas por modelos desenvolvidos a partir de um baixo investimento público influenciados por organismos multilaterais. A autora então, em seu artigo ordenou os resultados de sua pesquisa em dois períodos: décadas de 1970 e 1980 quando tivemos uma grande influência de diferentes organizações multilaterais como Unesco e o Unicef; e década de 1990 com a preponderante influência do Banco Mundial.

Ainda de acordo com Rosemberg (2002), a influência da Unesco e do Unicef girou em torno da circulação de ideias entre formadores de opinião e tomadores de decisão no plano das políticas brasileiras e pouco financiamento direto de projetos para programas de educação infantil.

No entanto, no caso do Banco Mundial sua influência se fez sentir de forma mais aguda a partir da década de 90 mediante o aumento do volume de empréstimos. E apesar da ampliação do atendimento, isso não ocasionou uma maior qualidade nos atendimentos gerando o que Rosemberg (2002) chamou de "educação para a subalternidade" a partir da redução ou contenção dos gastos públicos. Assim, são poucos ou quase inexistentes os investimentos para o aperfeiçoamento das profissionais e consequentemente para o oferecimento de um atendimento de melhor qualidade.

Segundo Penn (2002) a criança para o Banco Mundial é o capital humano do futuro, justificando o interesse do banco por este segmento por meio de políticas como o ECD (Early Childhood Care and Development $)^{3}$ em todo o mundo, visando a intervenção em problemas de desenvolvimento da criança, como a desnutrição, o desenvolvimento cognitivo deficiente e o despreparo para a educação primária, pois promovendo intervenções precoces diminuiria a possibilidade de fracasso na escola, pois se o cérebro desenvolve-se bem, isso aumenta as chances de um melhor aprendizado.

Neste sentido, Penn (2002) critica as políticas neoliberais, pois muitos autores associaram essas políticas (particularmente quando introduzidas abruptamente) ao crescimento da pobreza e ao sofrimento das crianças, pois estas são mais diretamente afetadas pela pobreza como também são particularmente susceptíveis a cortes nos serviços de infraestrutura como, por exemplo, nas áreas da saúde e educação gerando um número expressivo de crianças que morrem ao nascer ou logo depois, estimado em 7 milhões em todo o mundo.

${ }^{3}$ Desenvolvimento e Cuidado na Primeira Infância. 
Desta forma, as pesquisas têm mostrado que as políticas públicas giram em torno de programas produzidos a baixo custo que não prevê a formação especializada de educadores, uma organização satisfatória do espaço e disponibilidade de materiais diversificados visando a redução de investimentos em educação infantil e também segundo Rosemberg (2002), buscando um atendimento de massa.

Podemos pensar a respeito do aumento da escolarização para nove anos, com a entrada das crianças de 4 anos no ensino fundamental, que antes faziam parte da educação infantil. Seguindo o raciocínio de Rosemberg, poderíamos questionar essa entrada precoce que também é um dos fatores que podem contribuir para a diminuição de investimentos na educação infantil e, que ao pretender prevenir o fracasso escolar, na realidade visa a diminuição de gastos com essa criança, já que o custo da Educação Infantil é maior do que o custo da criança nas séries iniciais.

Nesta época de capitalismo global com um sistema econômico que produz desemprego e que não considera as políticas redistributivas, essa configuração que lhe é constitutiva, está quebrando a aliança histórica entre o mercado, o Estado-Providência e a democracia, características do Estado nacional na modernidade que visava a coesão social por meio de políticas universalistas do Estado-Providência associadas à cidadania e aos direitos humanos numa sociedade atravessada pela desigualdade e exclusão social.

O Estado Keynesiano segundo Santos (2005, p. 269) baseado no pleno emprego, na redistribuição e primazia da política social está perdendo campo para o Estado Schumpeteriano caracterizado pela inovação, competitividade, menos centralizado e menos cosmopolita, que privilegia a política econômica em detrimento à política social, consistindo no movimento do welfare state para o workfare state.

No entanto, este modelo de regulação social não vigorou plenamente em todos os países como é o caso de Brasil e Portugal, pois nunca houve um pacto social democrático, mas apenas numa minoria de Estados no Atlântico Norte e, sobretudo, na Europa Ocidental. Santos (2005) designa os processos vividos por Portugal como um "quasi-Estado-Providência", mas encontra-se numa situação paradoxal, pois vive uma crise do Estado-Providência sem nunca ter tido um Estado-Providência.

Esta crise acarreta um esvaziamento político do conceito de cidadania principalmente entre os grupos marginalizados na sociedade e também na erosão da proteção institucional e os indivíduos são convocados a serem responsáveis por seus destinos, tornando-se gestores individuais de suas trajetórias sociais ${ }^{4}$ (Santos, 2005).

Neste sentido, de acordo com Dale e Robertson (2001, p. 127) o Estado procura reconstruir a base da sua legitimação despolitizando o poder do Estado em benefício dos indivíduos e dos grupos por meio de um mecanismo-chave que está presente no discurso neoliberal: homo-economicus, espírito empreendedor, sujeito empreendedor, responsabilidade e competição. Somando-se a esse discurso está o que os autores chamam de efeito difusão dos mercados livres onde a acumulação é considerada legítima.

No entanto, como nos colocam os autores, nem todos os serviços do Estado podem ser despolitizados através da criação de mercados, diante disso, para regular as próprias contradições da teoria

${ }^{4}$ Dale e Robertson (2001, p. 133) usam a expressão 'gerir o self' como uma das características do discurso e das práticas neoliberais; a noção de 'self' como gestor de escolhas. 
neoliberal, a solução dirige-se à responsabilidade comunitária, sendo que a própria ideia de comunidade foi reconstruída pelo Estado, visando "garantir que os interesses da comunidade teriam, sempre que necessário, prioridade sobre o interesse individual enquanto instituição governativa"5 (Dale e Roberson, 2001:128).

Para regular e atribuir responsabilidades buscando a redução do problema da legitimação do Estado, a comunidade, os mercados e o complexo sistema de auditorias criadas pelo Estado funcionam como meios poderosos para a garantia do controle e coesão social (Dale e Robertson, 2001).

Desta forma, detendo-nos nos impactos negativos gerados pela globalização social e econômica, podemos considerar que os países periféricos veem sua situação agravada pelas políticas de ajustamento estrutural. Essas políticas diminuem drasticamente o financiamento para a área da educação, especialmente a educação infantil que apresenta um crescimento inferior aos demais níveis de ensino no Brasil.

Em relação à essa questão devemos considerar os aspectos excludentes de contingentes da população infantil a partir dos recortes de raça, classe, gênero e também idade. Este direito elementar das crianças a educação é negado no Brasil. Somente 30,4\% das crianças brasileiras estavam nas creches em 2015, segundo o último relatório divulgado pelo observatório do PNE. Em números absolutos, isso significa que aproximadamente 3,5 milhões de crianças estão em creches e mais do que 7 milhões estão fora. Quem está fora da escola? As crianças de zero a 3 anos. As pobres e as negras. E na pré-escola? $90,5 \%$ em 2015.

Assim, a questão da qualidade da educação infantil vem também atrelada à questão do quantitativo de vagas, pois a ampliação é essencial para se garantir que as crianças tenham acesso à creche e pré-escola. Desde 1991Rosemberg utilizando as PNADs 82, 85 e 87 sobre creche, pré-escola e séries iniciais do $1^{\circ}$ grau, apresentou que há diferenças entre as trajetórias de crianças brancas e negras $(0$ a 9 anos), mesmo quando foi possível controlar o rendimento familiar; a carreira de educação inicial de crianças negras, "é por vezes frustrada, por não ter acesso; acidentada, porque interrompida; retomada ou abandonada e sofrida, porque tende a ser de pior qualidade" (Rosemberg, 1991, p. 30).

Os dados também sugerem que as alternativas de creches e pré-escolas onde encontramos o maior número de crianças pobres são aquelas onde estão o maior número de crianças negras; Rosemberg (1991), destaca duas informações observadas no Estado de São Paulo: um número considerável de crianças que repetem a $1^{\text {a }}$ série do $1^{\circ}$ grau é negro (39\%); e as crianças negras tendem a frequentar, mais que as brancas, escolas que oferecem cursos com curtas jornadas diárias.

Kappel, Carvalho e Kramer (2001), em sua pesquisa sobre o perfil das crianças de 0 a 6 anos que frequentavam creches, pré-escolas e escolas a partir dos resultados da pesquisa sobre padrões de vida do IBGE, concluíram que no que se refere à cor, o acesso de crianças brancas à educação infantil mostrou-se maior que o de pretas/pardas, o que segundo as pesquisadoras "configura um contexto onde a discriminação está presente, confirmando resultados de outras pesquisas realizadas" (Kappel, Carvalho e Kramer, 2001, p. 46).

${ }^{5}$ Dale e Robertson (2001:131) apresenta-nos como exemplo da comunidade enquanto instituição governativa, o funcionamento dos mercados no setor da educação na Nova Zelândia, mostrando que aumentou a competição entre as escolas visando ganhar um número cada vez maior de 'consumidores', transformando este espaço num verdadeiro 'clube de famílias semelhantes e da mesma classe social, cujo único interesse comum é a proteção dos privilégios educativos' gerando assim, escolas excluídas que são encaradas como riscos. 
Os atuais dados considerando o Plano Nacional de Educação 2014-2023 se apresenta promissor em relação à possibilidade de universalização do acesso à pré-escola principalmente quando consideramos a obrigatoriedade da matrícula a partir dos quatro anos de idade, mas em relação à creche os dados ainda continuam preocupantes e extremamente excludentes em relação ao atendimento a essa faixa etária. Assim, a política da educação infantil no Brasil ainda está pautada nas desigualdades econômicas, sociais, regionais, raciais, de gênero e também de idade.

A lógica do capital desconfigura toda a construção teórica produzida pelos vários discursos já apresentados anteriormente sobre a infância desde a Pedagogia, a Medicina, a Psicologia, a Sociologia e a Filosofia, pois cada um em sua perspectiva criaram um bolsão cultural de proteção de crianças educadas, felizes, sadias, sociáveis, cidadãs evitando que estas se desviassem deste projeto idealizado de infância para não se tornarem, por exemplo, um produto marginal do tráfico, resultado este da ação do capital que se mostra em toda a sua dureza na vida das crianças.

Estes discursos pedagógicos, médicos, psicológicos, sociológicos e filosóficos buscam prevenir/controlar e forjar uma subjetividade produzindo uma essência nas crianças, onde aquelas que se desviam são crianças-risco, crianças perigosas. Essas crianças classificadas a partir de um "desvio" da norma têm a possibilidade de fazer fugir, fazer vazar os modelos de saber/poder hegemônicos

O Capital e a biopolítica ${ }^{6}$ atuam sobre a vida e se configuram como uma forma desoberania que abocanham tudo, pois o capital é inclusivo e expansivo, sendo que ao mesmo tempo em que busca preservar a vida da criança enquanto 'capital humano do futuro' também joga-a no risco devido sua própria constituição produzindo a criança-risco.

Precisamos considerar que toda legislação tornada política pública em relação à infância no Brasil a partir de finais do século XIX diz respeito à criança pobre e negra, considerada como um problema social a ser combatido.Donzelot (1986, p. 79) utiliza as terminologias 'infância em perigo’ para designar aquilo que pode ameaçar a infância e 'infância perigosa’ para se referir àquilo que pode torná-la perigosa.

Essas crianças passam a serem vistas como uma ameaça, como inimigos da sociedade, pois apresentam um comportamento que não condiz com as normas estabelecidas e precisam ser controlados para não gerarem sentimentos de horror/pânico na sociedade com suas atitudes.

É uma ameaça à ordem moral, aos valores tradicionais que suscita um controle maior feito por condenações longas, sanções, coações, ou seja, há um aumento das medidas de controle visando a proteção da sociedade que se sente ameaçada, mas há também medidas educativas visando a prevenção de atos perigosos:

todavia, a questão do que é apropriado socialmente e o controle legal das responsabilidades partem quase que inevitavelmente acompanhado de pânico moral. E a legislação aplicada é vista somente como um primeiro passo; pois para outros que o comportamento em questão é visto como uma ameaça, medidas como educação, socialização, mudanças nas normas, prevenção, tratamento e curas serão sugeridas e debatidas (Goode e Ben-Yheuda, 2003, p. 32).

${ }^{6}$ O termo Biopolítica, o poder sobre a vida, foi cunhado por Foucault e refere-se à lógica do capital sobrepondo-se ao corpo e à vida. Trata-se do poder que se apropria da vida e a produz. Dessa forma, o corpo é uma realidade biopolítica e, para Foucault, a lógica do biopoder é que ele faz viver e deixa morrer. 
Assim, o Estado brasileiro a partir do final do século XIX propõe medidas de assistência e proteção, medidas estas de controle visando assegurar o impacto que o próprio capitalismo suscita sobre as crianças. Na sociedade disciplinar a correção dos 'infratores' era feita por meio do aprisionamento, na sociedade atual, de controle, a correção prevê medidas voltadas para a educação dessas crianças e prevenção de comportamentos desviantes como vimos com Goode e Ben-Yehuda (2003).

Nesse sentido, quando pensamos sobre o processo de socialização da criança negra antes da sua inserção na instituição escolar, o trabalho era a forma principal de socialização dessa criança, mas a partir do momento em que ingressa na escola essa socialização passa a ocorrer nesse novo lugar que se configura como um equipamento de ensino que não acolhe a sua diferença, a sua particularidade cultural e que em diversas situações lhe impossibilita a permanência por se basear em um único modelo de indivíduo e de cultura a partir de um protótipo de infância e de criança.

$\mathrm{Na}$ discussão a seguir abordaremos as legislações e as políticas públicas decorrentes para a infância a partir do século XIX até a contemporaneidade apresentando informações que corroboram com as afirmações apresentadas anteriormente sobre a produção da criança negra enquanto "criança problema", uma desviante na sociedade brasileira e de como o trabalho sempre foi a tônica para a salvação dessa infância pobre e negra que poderia ser recuperada por meio de uma ensino profissionalizante e inserida novamente na sociedade.

\section{Infância e Direitos}

$\mathrm{Na}$ Europa, mais especificamente na França as normas protetoras da infância segundo Donzelot (1986) se multiplicaram como, por exemplo: lei sobre o trabalho de menores (1840-41); lei sobre a insalubridade das moradias (1850); lei sobre o contrato da aprendizagem (1851), sobre a vigilância das nutrizes (1876), sobre a utilização de crianças pelos mercadores e feirantes (1874) e sobre a obrigatoriedade escolar (1881).

Nesta intervenção do Estado na infância também vemos uma forma de controle da família como bem nos mostrou Donzelot (1986). Ocorreu um movimento denominado por Donzelot (1986) de conservação das crianças a partir de meados do século XVIII, no entanto, essa conservação seguirá caminhos opostos quando relacionada à família rica e à família pobre.

Nas famílias ricas ocorre uma ligação entre elas e os médicos que elaboraram uma série de livros sobre a arte de cuidar na primeira infância sobre criação, educação e medicação das crianças, ou seja, há uma preocupação com a proteção do corpo (economia do corpo). Por outro lado, nas famílias pobres tratava-se de entravar o abandono de crianças em hospícios para menores, de controlar as uniões livres e de impedir a vagabundagem dos indivíduos, principalmente das crianças, visando em tudo isso segundo Donzelot (1986. p. 27) "não mais assegurar proteções discretas, mas sim, de estabelecer vigilâncias diretas", ou seja, tratava-se de um controle sobre o corpo (economia social).

É a época na qual pela primeira vez ouve-se falar em salário-família cujo objetivo era fazer com que as mães cuidassem de seus filhos ao invés de abandoná-los e, criar assim, um ônus para o Estado com o recolhimento dessas crianças. Isso é o que Donzelot (1986) denominou de "economia social" por meio da 
filantropia como uma solução ao pauperismo e ao aumento dos indigentes que exigiam do Estado mais subsídios; dessa forma, a filantropia em substituição à caridade veio livrar o Estado dessas despesas remetendo para a esfera privada as demandas que the eram formuladas em termos de direito ao trabalho e à assistência.

Como viemos de um passado escravista não muito distante, podemos deduzir que a intervenção do Estado brasileiro na infância não é um fato muito antigo, pois a título de comparação podemos citar a já citada obrigatoriedade escolar na França em 1881, nesse período, no Brasil ainda não havia sido sancionada a Lei Áurea, que ocorreu em 1888. Houve uma lei antes ainda durante o período escravista envolvendo a questão da infância negra, que poderia na visão de alguns ter beneficiado as crianças negras, já que estas eram os sujeitos da referida lei, que foi a Lei do Vente Livre de 1871.

Uma lei que não contribuía com a emancipação das crianças negras, pois como estas poderiam viver sua liberdade sem seus pais, estas acabavam ficando nas fazendas e tornando-se da mesma forma propriedade do senhor da fazenda. Dados que são confirmados pela pesquisa de Fonseca (2001). E como libertar uma parte apenas do corpo da mulher, o seu ventre?

A Lei do Ventre Livre (1871-1888) foi utilizada por Fonseca (2002) como parâmetro para o desenvolvimento da pesquisa, a partir da qual foi possível verificar que houve uma articulação entre libertação e educação, sendo que esta última, chegou a ser tratada como uma dimensão complementar do processo de abolição do trabalho escravo, cujo objetivo era "minimizar o impacto que o fim do trabalho escravo poderia gerar no perfil da sociedade brasileira, que receberia um número significativo de indivíduos originários do cativeiro na condição de cidadãos livres" (ibid, p.13).

A partir da Lei do Ventre Livre, todas as crianças passaram a ser consideradas livres, no entanto, deveriam permanecer segundo Fonseca (2002, p. 19) até os oito anos sob a posse dos senhores de suas mães e, quando chegasse a essa idade, o senhor decidiria se ficaria com a criança até completar vinte e um anos ou a entregaria ao Estado mediante indenização de seiscentos mil réis.

Segundo Fonseca (2002) a partir do momento em que a lei foi aprovada começaram as propostas para a constituição de associações para a educação das crianças nascidas livres, que passaram a ser apresentadas ao Ministério da Agricultura. No entanto, para surpresa geral, de acordo com Fonseca (2002) seis anos após a primeira geração de crianças completar a idade que possibilitaria ao senhor escolher entre ficar como a criança ou entregá-la ao Estado, o número total de crianças nascidas livres de escravas existentes em todo o Brasil era de 403.827, sendo que dessas, apenas 113 haviam sido entregues ao Estado.

A partir de relatos de viajantes europeus, ao Rio de Janeiro, no período de 1800 a 1850, Mott (1979) reconstitui as condições em que eram mantidas crianças escravizadas. O estudo trata, por exemplo, de seu relacionamento com a mãe, com seus senhores, das atividades de trabalho que realizava, do valor que lhes era atribuído para compra e venda, uma vez que, eram consideradas semoventes.

Segundo as descrições de viajantes, os senhores tratavam as crianças escravizadas consideradas, até seus cinco ou seis anos de idade, como uma espécie de animalzinho doméstico, com certo afeto. A partir dessa idade, as crianças passavam a desempenhar atividades consideradas como trabalho: descascar mandioca, descaroçar algodão e arrancar ervas daninhas. 
Nas ilustrações desenhadas pelos viajantes, os meninos maiores são representados, entre outras tarefas: carregando algum objeto pertencente a seu dono, por exemplo, guarda-chuva, trouxa de roupa, velas para pagar promessas; levando recados; fazendo pequenas compras. Já as meninas aparecem levando objetos da sua senhora, ajudando na cozinha, a servir a mesa ou cuidando de crianças filhas dos senhores. A preferência dos proprietários de crianças escravizadas era por crianças mestiças, tidas como mais inteligentes e preferidas para o serviço doméstico. Com sua venda obtinha-se melhor preço.

Por volta dos doze anos as meninas e os meninos escravizados eram vistos como adultos, no que se refere ao trabalho e à sexualidade. Muito raramente tinham acesso à alfabetização. Assim, podemos ver que se a infância branca no Brasil só passou a ser celebrada após a República, a infância negra sofreu e ainda sofre um descaso devido às desigualdades de uma sociedade, na qual o racismo sobrevive estruturalmente.

Em 1891, a Assembleia Nacional promulgava o direito da criança à instrução primária gratuita, no entanto, isentavam os extremamente pobres, contribuindo para o aumento da desigualdade entre brancos e negros, já que havíamos saído recentemente de uma estrutura escravista que, com seu fim não ocorreu uma efetiva integração do negro na sociedade brasileira. Ainda em 1891, Deodoro da Fonseca promulgou o decreto-lei número 1.313, que regularizava o trabalho infantil nas fábricas do Rio de Janeiro, fixando limite de idade e jornada de trabalho.

Já em 1921 poderíamos dizer que a criança negra passou a ser considerada, , a partir do problema da delinquência que vem atrelado à questão social e consequentemente à questão racial também. A Lei 4.242 do Judiciário modificou o Código Civil de 1917 como objetivo de definir 'menor abandonado', que marcou segundo Nunes (2003, p. 115) "a entrada direta do Judiciário no tratamento da criança pobre" e podemos acrescentar, negra. Em 1923, houve a criação do Juizado de Menores, quatro anos, em 1927, temos a promulgação da Lei 17.943 pelo Poder Judiciário houve a criação do primeiro Código de Menores.

Em 1934, proíbe-se o trabalho a menores de 14 anos; o trabalho noturno a menores de 16 anos; o trabalho a menores de 18 anos em ambientes industriais insalubres. Em 1937, o Estado responsabilizouse pela obrigatoriedade dos ensinos primários e pré-vocacional gratuitos paras crianças pobres. Já em 1938, o governo cria a casa do jornaleiro que foi um serviço que antecedeu a criação do SAM (Serviço de Atendimento ao Menor) - neste período de acordo com Nunes (2003, p. 117) "a infância passou a ser tratada como problema nacional”, especificamente a infância pobre na qual se insere a criança negra.

As instituições que mais de perto atuaram na área de atendimento às crianças de 0 a 6 anos no Brasil através de creches foram de acordo com Vieira (1988), o Departamento Nacional da Criança DNCr (a partir de 1940), o Ministério da Educação e Saúde, a Legião Brasileira de Assistência (LBA) e a Fundação Nacional do Bem-Estar do Menor (FUNABEM).

A LBA foi criada em 1942 e seus objetivos previam o desenvolvimento de serviços de assistência social estabelecendo convênios com creches. Era um programa nacional, atendia prioritariamente a população pobre e era orientado por uma concepção preventiva e compensatória de atendimento infantil (Campos e Ferreira, 2001, p. 37). 
A FUNABEM foi instituída em 1964 substituindo o Serviço de Atendimento ao Menor (SAM). Sua criação de acordo com Campos e Ferreira (2001) resultou de uma luta ainda iniciada na década de 40 por pessoas vinculadas ao governo e à Igreja que visavam uma reformulação no atendimento do menor abandonado cuja educação e recuperação era vista por estes setores como inadequada. A FUNABEM era orientada por uma concepção correcional-repressiva apoiada na construção de centros de internamento para crianças e adolescentes.

As duas instituições, LBA e FUNABEM atuavam em paralelo estabelecendo convênios com creches, no entanto, a partir dos questionamentos sobre o atendimento executado pela FUNABEM, propõe-se uma divisão de competências: a FUNABEM atenderia somente as crianças em situação de risco pessoal e social.

Em 1987, institucionalizou-se a Programa Bom Menino, cujo objetivo era a destinação ao trabalho do menor assistido com bolsa de iniciação ao trabalho. No ano de 1988, promulgou-se a Constituição Federal tendo sido bastante inovador ao considerar a criança o direito à vida, à saúde, à alimentação, à educação, ao lazer, à profissionalização, sendo dever da família e do Estado assegurar essas condições às crianças (art. 227).

Como podemos observar, estas instituições de atendimento à infância tinham um cunho educativo-corretivo e eram de acordo com Vieira (1988) propostas como um dispositivo para disciplinar mães e educar crianças nos preceitos da puericultura, como dispositivo de normalização da relação mãe/filho nas classes populares.

Kuhlmann Jr. (1998, p. 28), também se refere a esta questão da disciplinarização e controle da população pobre a partir de uma proposta educacional de baixa qualidade prevendo uma educação mais moral do que intelectual, pois

\footnotetext{
a história da assistência tem sido também a da produção de uma imagem do pobre como ameaça social a ser controlada (...) As instituições cumpririam uma função apaziguadora. Assim, o assistencialismo foi configurado como uma proposta educacional específica para esse setor social, dirigida para a submissão não só das famílias, mas também das crianças das classes populares (ibid).
}

Vemos então, a existência de dispositivos visando uma re-educação e controle, ou seja, o objetivo era corrigir e evitar os comportamentos desviantes. Assim, como aponta Foucault (2002, p. 84) "a penalidade no século XIX, de maneira cada vez mais insistente tem em vista menos a defesa geral da sociedade que o controle e a reforma psicológica e moral das atitudes e do comportamento dos indivíduos". Toda penalidade do século XIX passa a ser um controle sobre o que os indivíduos podem fazer, do que estão na iminência de fazer, tendo a periculosidade como a grande noção da criminologia e da penalidade em fins do século XIX (Foucault, 2002, p. 85).

No ano de 1990 tivemos a criação do Estatuto da Criança e do Adolescente (ECA) em substituição ao Código de Menores de 1927 que, segundo Nunes (2003, p. 120) “substituiu a doutrina da 'situação irregular' (de crianças em conflito com a lei) pela doutrina sócio-jurídica de proteção integral proposta pela ONU”. 
Essa doutrina proposta pela ONU está baseada na história dessa organização em relação aos direitos da criança que, culminou em 1989 com a aprovação da Convenção sobre os Direitos da Criança e foi de grande influência para a elaboração e ratificação do ECA no Brasil.

Em 1948a Assembleia Geral da ONU adotou a Declaração Universal dos Direitos do Homem, mas em relação às crianças, a primeira versão de um documento oficial sobre seus direitos foi formulada por Eglantine Jebb7 ${ }^{7}$ Em fevereiro de 1923, a Declaração foi adotada pela Internacional Save Children Union, instituição também criada por Eglantine (que mais tarde se tornou o International Union for Child Welfare), que recebeu o título de Declaração de Genebra. E em 27 de setembro de 1924, a Declaração foi adotada pela Liga das Nações, sendo o primeiro instrumento jurídico internacional à respeito da criança, mas sem valor de lei.

Em 1959, vinte e cinco anos após a incorporação da Declaração de Genebra, a ONU lançou o segundo documento de proteção e cuidado em relação à criança denominado Declaração Universal dos Direitos da Criança, incluindo de maneira específica o direito da criança à educação, cuidados de saúde e à proteção especial, mas também não tinha força de lei junto aos países membros, pois era apenas uma declaração. Visava criar uma proteção mais ampliada que a Declaração anterior, mas também devido aos motivos de guerra no período da Segunda Guerra Mundial.

No ano de 1978 o Governo da Polônia durante a 34a Sessão da Comissão dos Direitos do Homem apresentou uma proposta no sentido de que as Nações Unidas adotassem uma Convenção sobre os Direitos da Criança. Esta proposta da Polônia consistia em uma homenagem a JanuszKorczac (HenrykGoldszmit) ${ }^{8}$, um médico pediatra e educador que se tornou conhecido internacionalmente, pois se recusou a salvar sua própria vida tendo como motivo sua devoção à causa das crianças quando, em 1942, acompanhou um grupo de 200 órfãos retirados do gueto de Varsóvia até o campo de concentração de Treblinka, onde foi morto junto com as crianças.

O texto apresentado era bem semelhante à Declaração de 1959 e foi alvo de muitas críticas e não chegaram a um consenso, pois muitos declararam que a linguagem do texto não era apropriada, que não lidava com uma série de direitos e que por isso era omisso em muitos sentidos. No ano de 1979 a Comissão dos Direitos do Homem decidiu submeter o texto polaco a um exame detalhado e a um conjunto de modificações e, para isso decidiu criar um Grupo de Trabalho com uma composição ilimitada sobre a questão da Convenção sobre os direitos da criança.

Esta composição "ilimitada" do Grupo de Trabalho visava que todos os Estados membros da Comissão dos Direitos do Homem nele pudessem participar e que todos os outros Estados pudessem enviar observadores, os quais teriam o direito de fazer intervenções. A fase de redação foi muito complicada devido às diferenças entre os Estados membros relacionados às questões de religião, liberdade de opinião, às minorias étnicas, etc.

${ }^{7}$ Internacionalmente em prol da criança vemos inicialmente a ação de uma mulher fundadora da instituição Save the Children em 1906, seu nome é Eglantine Jebb. Após a Primeira Guerra Mundial, Eglantine tornou-se a mulher com o melhor conhecimento a respeito dos direitos das crianças, pois ajudou no combate à miséria vivida no pós-guerra por milhares de crianças em toda a Europa.

${ }^{8}$ Paralelamente ao seu trabalho de médico, começou a organizar colônias de férias para crianças de famílias operárias e órfãs. 
Entre os anos de 1980 e 1987 o Grupo de Trabalho reuniu-se uma vez por ano, tendo concluído seu trabalho em 1989, ano que a Convenção foi adotada. A Convenção sobre os Direitos da Criança foi adotada em 20 de novembro de 1989, esta data foi decretada pela ONU como Dia Universal da Criança.

A ONU toma a infância como capital humano do futuro, mas na verdade não foi uma grande novidade, pois esta agência abarcou os discursos que já vinham sendo produzidos há muito tempo. A novidade estaria no fato de esta agência ter organizado todos estes temas que já vinham sendo discutidos em torno de tratados jurídicos que adquiriram um sentido global, universalizante. A ideia do direito é a grande novidade na história discursiva sobre a criança e a infância.

A Declaração Universal dos Direitos do Homem produzida pela ONU é o grande modelo de Declaração para as demais que foram construídas posteriormente, pois abriu a possibilidade sem precedentes de se incorporar todos os seres humanos sem distinção de raça, cor, credo religioso ou político, classe, riqueza, poder, gênero, geração, nacionalidade, deficiência ou situação econômica, política, social ou cultural que puderam ser constituídos enquanto sujeitos portadores de direitos, pois sabemos que há uma grande quantidade de pessoas fora de qualquer cidadania como, os miseráveis, por exemplo.

Isso nos ajuda a esclarecer a incorporação nos documentos da ONU para a criança de questões como a introdução dos direitos da criança deficiente, da proteção de seus direitos independente de qualquer situação em que esteja inserida, da sua raça, etnia, etc. Temos que considerar também a mudança dos contextos, pois nos últimos anos passamos por transformações que também influenciaram a inclusão de outros segmentos da sociedade historicamente excluídos. Podemos citar os seguintes fatores: novas formas de acumulação de capital; mudança nos processos de produção; fim das fronteiras dos Estados-nação; aumento dos conflitos sociais (gênero, étnico, racial, religioso). Tudo isso contribuiu para o aparecimento de novos direitos e da inserção de novos grupos dentro deste campo de direitos como é o caso das crianças.

Tudo isso contribuiu de acordo com Norberto Bobbio (2004) para a compreensão de que os direitos do homem não podiam se pautar na compreensão de um homem genérico, mas sim considerá-lo especificamente considerando a diversidade dos contextos em que os homens se inserem, justificando um tratamento diferenciado para as mulheres, os idosos, as crianças, os deficientes, pois possuem necessidades específicas.

A ONU construiu a partir de seus documentos uma tendência universalizante ou globalizante dos discursos sobre os direitos da criança que foi iniciada em 1924 com a Declaração de Genebra adotada pela Liga das Nações e, posteriormente em 1959 e 1989 tivemos a ampliação e reformulação desses direitos com a Declaração e a Convenção sobre os Direitos da Criança pela ONU.

O discurso jurídico não somente afirma o lugar da infância, a particularidade da criança, mas o assegura na medida em que produz a criança como portadora de direitos, superando assim o debate sobre o sentimento da infância, pois na medida em que para se ter direito é preciso constituir alguém como 'sujeito e ator social', se desprende a criança da família colocando o debate em outro patamar no interior da ideia de autonomia da criança em relação aos adultos. 
Reconhece-se definitivamente e assegura-se juridicamente o sentimento da infância, a criança passa a ser considerada em sua particularidade. Neste sentido, a Sociologia da Infância tem grande importância para fazermos esta reflexão, pois constituiu a criança como ator social e, consequentemente, portador de direitos.

A Sociologia ainda não tinha reservado às crianças uma atenção específica, pois sempre eram estudadas como um fenômeno interligado à escola e à família e atrelada à discussão sobre a socialização da criança como uma forma de inculcação dos valores da sociedade adulta, permanecendo durante um longo período presa à definição durkheimiana de imposição dos valores adultos sobre a criança levando estas a permanecerem em uma posição marginalizada e passiva diante do mundo adulto.

Com a proposição de um outro modelo de socialização baseado numa concepção interacionista foi possível considerar a criança "como sujeito social, que participa de sua própria socialização, assim como da reprodução e da transformação da sociedade" (Mollo-Bouvier, 2005, p. 393). A abertura no campo sociológico e a utilização de um outro conceito de socialização possibilitou o surgimento da Sociologia da Infância e uma nova perspectiva de compreensão da criança como um ator social.

A ONU ao carregar este discurso produz a criança portadora de direitos com a criação dos seus três documentos para a criança (Declaração de Genebra de 1924, a Declaração dos Direitos da Criança de 1959 e a Convenção sobre os direitos da Criança de 1989) e deslocará o discurso histórico sobre a infância, que vinha sendo feito desde Ariès (1986), para o discurso jurídico, pois mais do que a especificidade da criança como bem afirmou o discurso histórico; o discurso jurídico partirá desta especificidade tomando a criança como portadora de direitos.

Esta jurisprudência tem por estratégia teórica e política salvaguardar a infância como capital humano do futuro. Assim, o que está em jogo não são os elementos da história, pedagogia, medicina, filosofia ou sociologia ou psicologia, mas a economia a acumulação do capital que começa na infância, pois o discurso jurídico se pauta também na economia. O discurso jurídico toma o corpo da criança e este deve ser cultivado, formado, reformado, corrigido e controlado para que possa desenvolver determinadas aptidões, qualidades para o trabalho futuro, ou seja, é a formação de um corpo como força de trabalho.

Desta forma, é precisamente ao lado da ONU e sua organização jurídica em relação à criança que nós veremos intercambiar-se a mecânica da disciplina e o princípio do direito. O desenvolvimento de todo um aparato de controle, proteção, cuidado e gestão de vidas ocorre no encontro desses dois campos heterogêneos da disciplina e da soberania.

Para Foucault (2005, p. 47) "soberania e disciplina, legislação, direito da soberania e mecânicas disciplinares são duas peças constitutivas dos mecanismos gerais de poder em nossa sociedade”. A criança 'portadora de direitos' e a infância enquanto capital humano do futuro se constituem como uma noção jurídico-disciplinar, pois se encontram no cruzamento da dupla referência, jurídica e disciplinar, ou seja, a soberania e a normalização que ela produz. 


\section{Em direção à multidão}

A ação estatal das políticas públicas em relação à criança se insere no conjunto de dispositivos existentes para a regulação das populações infantis por meio do controle e normalização tendo como forte recorte a questão de idade, classe e raça que, passa a se configurar como uma nova forma de conceber esse segmento populacional, com o intuito de gerir e controlar justificados pela preservação de sua vida, ou seja, em prol da vida para torná-la mais produtiva, saudável e feliz.

A criança 'portadora de direitos' e a infância enquanto 'capital humano do futuro' se configurarão como o efeito dessa intrincada rede de poderes constituída pela ONU enquanto uma organização que possui um poder polimorfo, pois detém um poder econômico, político e judiciário.

Uma trama de subjetivação, que lhe confere um dado lugar, uma subjetividade e práticas que a governam e que produzirão a criança "normal", sadia, educada, brincante, cuidada no seio de uma família que lhe assegure um ambiente de afeto e com segurança moral e material e a criança anormal (em conflito com a lei; a criança-risco; ou delinquente).

Ao mesmo tempo em que o dispositivo separa as crianças por meio da norma entre normais e anormais, ele as une, as homogeneiza enquanto capital humano do presente, como um grupo que consome (ou seja, enquanto consumidoras), e também, enquanto acumulação do capital(o adulto produtivo) que não importa a cor, o sexo, a nacionalidade, pois segundo Foucault (2002a , p. 154) "o poder de regulamentação obriga à homogeneidade; mas individualiza, permitindo medir os desvios, determinar os níveis, fixar as especificidades e tornar úteis as diferenças ajustando-as umas às outras".

Essas medidas de prevenção/controle são utilizadas para a transformação dessas "crianças-risco de multidão" para povo, conceitos esses utilizados por Hardt e Negri (2002, p. 120), pois o "povo é algo uno, tem uma identidade, é homogêneo, que supõe uma vontade geral, é um produto do Estado-nação, diferentemente da 'multidão' que se configura como uma multiplicidade", um conjunto aberto de relações, que não é idêntica e nem homogênea a si mesma, que não é controlável, por isso, segundo os autores, "toda nação precisa fazer da multidão um povo" (ibid).

Essas crianças classificadas a partir de um "desvio" da norma têm a possibilidade de fazer fugir, fazer vazar os modelos de comportamento, de estética, de sexualidade, de ser utilizados como padrão a partir dos quais todos os outros são avaliados e validados ou não. As diferenças que fazem fugir o povo com suas regras de unificação. Nesse caso, povo não mantém relação de exterioridade com o fora, pois tudo deve reverberar em padrões hegemônicos e em um único território.

De acordo com Hardt e Negri (2002, p. 174),

o pobre é indigente, excluído, reprimido, explorado e ainda assim está vivo. É o denominador comum da vida, o fundamento da multidão (...) entretanto, a corrente dominante da tradição marxista sempre odiou o pobre, justamente por ele ser 'livre como um pássaro', por ser imune à disciplina da fábrica e à disciplina necessária para a construção do socialismo.

'Virno (2001) também utiliza o conceito de 'multidão' como uma categoria analítica visando a análise das formas de vida do homem pós-moderno. O termo 'multidão' foi utilizado pela primeira vez por Espinosa (1677) que, segundo Virno (2001:04) seria "como um pai putativo" desse conceito. 
Assim também são as crianças quando se tornam o próprio risco, ou seja, crianças-risco, elas deixam de ser povo e passam a ser multidão, eram algo que se podia controlar, depois se tornam incontroláveis, se tornam máquinas de guerra contra o aparelho de sobrecodificação do Estado. Máquinas de guerra que destroem a si mesmas, mas também tudo que está ao redor, pois o capitalismo as transformam em fiapos e depois em granadas que podem fazer explodir tudo, é pura barbárie, é morte.

As crianças-risco são compostas de linhas de fuga, são potência pura, por isso se transformam em máquinas de guerra em oposição aos controles e à sobrecodificação do Estado que é sempre molar. Essa linha de fuga se constitui de acordo com Hardt e Negri (2002) como uma recusa, que se configura como uma forma de subversão ao poder soberano, à máquina de sobrecodificação.

Novo corpo e nova vida que produza segundo Hardt e Negri (2002) uma noção nova e positiva de barbárie, já que esse novo bárbaro

\begin{abstract}
não vê nada permanente, mas justamente por isso, vê caminhos por toda parte. Onde outros encontram muros ou montanhas, ali também, ele vê um caminho. Mas porque vê um caminho em toda parte, ele tem de limpar esse caminho em toda parte... Porque vê caminhos em toda parte, ele sempre se coloca em encruzilhadas. Nenhum momento pode estar ciente do que o próximo trará. $\mathrm{O}$ que existe, ele reduz a entulho, não por amor ao entulho, mas por amor ao caminho que atravessa o entulho. Os novos bárbaros destroem com uma violência afirmativa e traçam novas trilhas de vida de sua própria existência material (Hardt e Negri, 2002, p. 235).
\end{abstract}

Desta forma, qual seria o caminho a se trilhar no trabalho com as crianças-risco para transformar sua violência-suicídio em uma violência afirmativa? Uma violência que ao invés de destruir, pode produzir algo, pode produzir vida nova, sentimentos novos e caminhar em outra direção que não a do controle, da homogeneização, da dominação, de transformar o outro num mesmo de mim, mas produzir diferenças, misturas, mutações. Esse é o mesmo caminho para se pensar as políticas públicas para as crianças brasileira considerando sua diversidade de vida e contextos.

"Não é concebível um pensamento crítico que não seja também, em quaisquer de suas facetas, uma meditação sobre a infância” (VIRNO, 2012, p. 34).

\title{
Referências
}

ALAIN (1932). Propos sur l 'éducation: PUF, Paris 1976.

APPLE, M. W. Políticas de direita e branquidade: a presença ausente da raça nas reformas educacionais. In: Revista Brasileira de Educação, n.16. p.61-67. Jan/2001.

ARIÈS, P. L'Enfant et la vie familiale sous l'ancien Régime, Seuil, PUF, Paris, 1973

BOBBIO, Norberto. A era dos direitos. Rio de Janeiro: Elsevier, 2004. 5a impressão. 
CAMPOS, Maria Malta; FERREIRA, Isabel M. \&Rosemberg, Fúlvia. Creches e Pré-escolas no Brasil. São Paulo: Cortez. Fundação Carlos Chagas, 2001.

DALE, ROBERTSON, Susan \& DALE, Roger. Regulação e Risco na governação da educação: gestão dos problemas de legitimação e coesão social em educação nos estados competitivos. In: Revista Educação, Sociedade \& Culturas, n. 15. p. 117-147. 2001.

DONZELOT, J., (1986). A Polícia das Famílias. 2a edição. Rio de Janeiro: Edições Graal. p.01-89.

FONSECA, M. V. da., (2001). As primeiras práticas educacionais com características modernas em relação aos negros no Brasil. In: Revista Negro e Educação. n.1. p.11-36.

FOUCAULT, M. A Verdade e as Formas Jurídicas. Rio de Janeiro: NAU Editora. 2002.

Vigiar e Punir. Petrópolis (RJ): Vozes, 2002a.

Em defesa da sociedade. São Paulo: Martins Fontes, 2005.

GOODE, Eric \& BEN-YEHUDA, Nachman. Moral Panics: the social construction of deviance. BlackwellPublishing. 2003.

HARDT, M. \& NEGRI, A., (2002). Império. Rio de Janeiro: Record. Trad. Berilo Vargas.

KAPPEL, M. D. B.; CARVALHO, M. C. \& KRAMER, S. Perfil das crianças de 0 a 6 anos que frequentam creches, pré-escolas e escolas: uma análise dos resultados da Pesquisa sobre Padrões de Vida/IBGE. In: Revista Brasileira de Educação, n. 16. Rio de Janeiro: Editores Associados, 2001. p.35-47.

KUHLMANN JR, M., (1998). Infância e Educação infantil: uma abordagem histórica. Porto Alegre: Mediação.

MOLLO-BOUVIER, Suzanne. Transformação dos modos de socialização das crianças: uma abordagem sociológica. In: Revista Educação \& Sociedade, Campinas, vol. 26, n. 91, p.391-404, Maio/Ago. 2005.

MO'T'T, M. L. B., (1979). Acriança escrava na literatura de viagens. In: Cadernos de Pesquisa, n.31. p.57-68.

NUNES, B. F., (2003). Sociedade e Infância no Brasil. Brasília: Editora Universidade de Brasília. 
PENN, H., (2002). Primeira Infância: a visão do Banco Mundial. In: Cadernos de Pesquisa. São Paulo. n.115, p. 07-24. Trad. Fúlvia Rosemberg.

QVORTRUP, Jens. Infância e Política. In: Cadernos de Pesquisa, v. 40, n. 141, p. 777-792. 2009.

ROSEMBERG, F. Organizações Multilaterais, Estado e Políticas de Educação Infantil. In: Cadernos de Pesquisa. São Paulo. n.115, 2002. p.25-63.

Raça e educação inicial. In: Cadernos de Pesquisa, n.77. 1991. p.25-34.

ROSSETTI-FERREIRA, M. C; RAMON, F. \& SILVA, A P., (2002). Políticas de atendimento à criança pequena nos países em desenvolvimento. In: Cadernos de Pesquisa. São Paulo. n.115. p.65-100.

SANTOS, Boaventura de Sousa. Os processos de globalização. In: (org). Globalização:

fatalidade ou utopia? Porto: Edições Afrontamento. p.31-99. 3a ed. 2005.

SARMENTO, Manuel Jacinto. Gerações e Alteridade: interrogações a partir da sociologia da infância. In: Revista Educação \& Sociedade. N. 91. Vol. 26. Mai/ago. 2005. p.361-378.

SILVÉRIO, V. R.A diferença como realização da liberdade. In: ABRAMOWIVZ, A; BARBOSA, M. L. de A. \& SILVÉRIO, V. R. Educação como prática da diferença. Campinas (SP): Armazém do Ipê (Autores Associados). 2006

VIEIRA, L. M. F., (1998). Mal necessário: creches no Departamento Nacional da criança (1940-1970). In: Cadernos de Pesquisa. São Paulo. N.67. p.03-16.

VIRNO, Paolo. Gramática da Multidão: para uma análise das formas de vida contemporâneas. Tese. Universidade de Calábria. Tradução: Leonardo Retamoso Palma. 2002.

Infância e pensamento crítico. Imprópria. Política e pensamento crítico, n. 2, 2012.

Recebido em: 14/08/2017

Aprovado em: 26/11/2017 